\title{
CTU Optical probes for liquid phase detection in the 1000 MW steam turbine
}

\author{
Michal Kolovratník ${ }^{1}$, Ondřej Bartoš ${ }^{1, a}$ \\ ${ }^{1}$ CTU in Prague, Department of Energy Engineering, Technická 4, Prague 6, 166 07, Czech Republic
}

\begin{abstract}
The aim of this paper is to introduce the measurement capacity of a new generation of CTU's optical probes to determine the liquid phase distribution in steam turbines and other energy systems. At the same time the paper presents the first part of the results concerning output wetness achieved through the use of experimental research performed with the probes in a new low pressure (LP) part of the steam turbine $1000 \mathrm{MW}$ in the Temelin nuclear power plant (ETE). Two different probes were used. A small size extinction probe with a diameter of $25 \mathrm{~mm}$ which was developed for measuring in a wider range of turbines in comparison with the previous generation with a diameter of $50 \mathrm{~mm}$. The second probe used was a photogrammetric probe developed to observe the coarse droplets. This probe is still under development and this measurement was focused on verifying the capabilities of the probe. The data processing technique is presented together with yielded examples of the wetness distribution along the last blade of the $1000 \mathrm{MW}$ steam turbine. The experimental measurement was done in cooperation with Doosan Škoda Power s.r.o. (DSP).
\end{abstract}

\section{Introduction}

The year 2014 offered the unique possibility for doing experimental research on the expanding steam in steam turbines, due to the operational launch of the innovative LP section of the $1000 \mathrm{MW}$ turbine on block 1 . in the Temelín nuclear power plant. This event together with the keenly awaited launch of the first Czech power plant at Ledvice with supercritical steam parameters ELE $660 \mathrm{MW}$ are great opportunities for the research of wet steam expansion which has long history on the CTU and in Czechia.

The manufacturer of both turbines is Doosan Škoda Power s.r.o. Thanks to the support of the manufacturer both turbine's LP part were equipped with measurement ports for pneumatic and optic measurement in the front and behind the last stage of the LP section of the steam turbine.

At the turn of August and September 2014 the first set of measurements was performed during the rise of the performance of the turbine after the first launch of the new turbine. DSP performed pneumatic measurements of the flow field and under a long-standing agreement CTU performed simultaneous measurements on the other side of the turbine with optical probes to determine the properties of the liquid phase in the wet steam flow. For this purpose two probes were used. The extinction probe determines the parameter of the fine droplets and the photogrammetric probe determines the parameter of the coarse droplets.
The main goal of the measurement was to collect experimental data from an actual machine which could help to enhance the operational properties, reliability and efficiency of the measured turbine. The data will be used for the design and engineering of future turbines as well.

\section{The measurement methods}

\subsection{Light extinction}

Data of the measured dependence of the light extinction for a specific light wavelength $I / I_{0}=f(\lambda)$ after passing through the layer of wet steam is collected in a specific position of the flow path in the steam turbine. The thickness of the layer in the turbine is defined by the measuring window of the extinction probe.

The measurement procedure with the extinction probe usually has two main stages. In the first stage the reference signal is acquired in order to know the dependence of the light intensity $I_{0}$ and wavelength $\lambda$ without any water droplets in the measurement section. Then follows the second stage of measurement in the wet steam and again the dependence of $\mathrm{I}$ and $\lambda$ is acquired. Due to the light scattering on the water droplets in the wet steam, the light intensity $\mathrm{I}$ is lower than $\mathrm{I}_{\mathrm{o}}$. An example of the acquired data can be seen in figure 1 .

By determining the extinction ratio $\mathrm{I} / \mathrm{I}_{0}=\mathrm{f}(\lambda)$ and applying the Mie theory of light scattering on water droplets one can find the size distribution of the droplets $\varphi(D)$ and the wetness of the wet steam y. In general the

\footnotetext{
${ }^{\mathrm{a}}$ Corresponding author: ondrej.bartos@fs.cvut.cz
} 
solution leads to a system of Fredholm integral equations of the first kind [1].

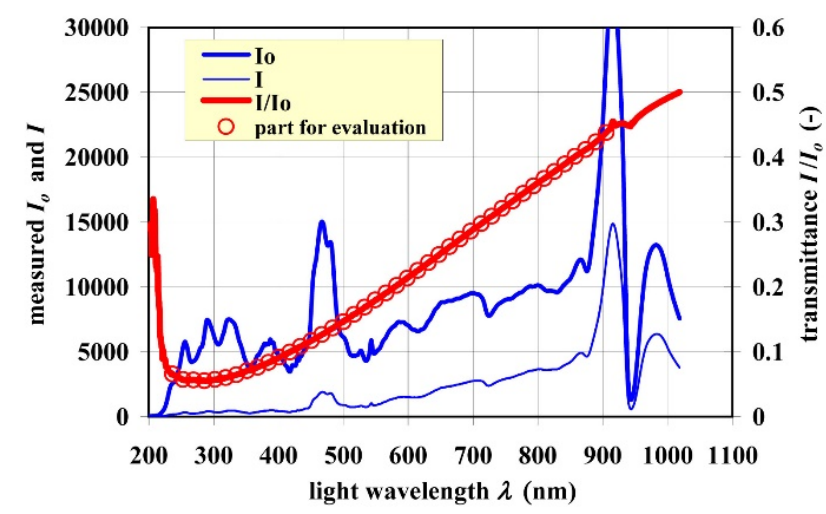

Figure 1. An example of the acquired and data processed data.

$$
\frac{1}{\ell} \ln \left(\frac{I_{o}}{I}\right)_{i}=\frac{\pi}{4} N_{v} \int_{0}^{D_{\infty}} \mathrm{Q}\left(\pi D / \lambda_{i}\right) \cdot \varphi(D) \cdot D^{2} \mathrm{~d} D .
$$

Where $\ell$ is the length of the measurement section of the probe, $N_{v}$ is the volumetric number density of droplets, $Q(\pi D / \lambda)$ is the extinction coefficient according to the Mie theory, $D$ droplet diameter, $\varphi(D)$ size distribution function of the droplets and $i=1,2, \ldots k$ is the chosen number of the particular wavelengths $\lambda_{1,2,3 \ldots k}$ and this presents the number of the equation in the system.

\subsection{Photogrammetric measurement}

Photogrammetry is a method for determining the object properties from an image captured by a camera [4]. The expected size of the coarse droplets in steam turbines is in a wide range of 1 to $500 \mu \mathrm{m}$. The magnification of the objective is limited by the minimum exposure time of the camera when a global shutter is used. Higher magnification can bring better resolution for smaller droplets, but the displacement of the droplet may then be bigger than the size of the observed volume when the picture is taken. The velocity of droplets can reach on average more than $200 \mathrm{~m} / \mathrm{s}$.

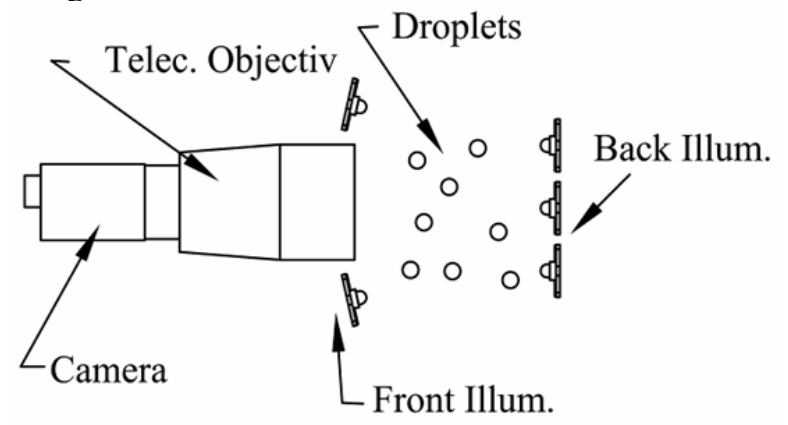

Figure 2. Schematic diagram of the measurement system.

The length of the path and the exposure time makes it possible to compute the velocity of the droplet and determines the expected direction of the droplet's movement. A telecentric objective provides the advantage that the image size is independent of the distance from the objective. Calibration is required for the correct pixel/dimension ratio [5].

\section{Measurement probes}

\subsection{Light extinction probe}

An extinction probe with the carrier tube with a diameter of $35 \mathrm{~mm}$, developed for expected measuring activity in the year 2015, was used for the measurement behind the last stage of the $1000 \mathrm{MW}$ turbine with the last blade length of $1220 \mathrm{~mm}$. The sealing section of the measuring port on the turbine's casing has a diameter of $51 \mathrm{~mm}$. The $2 \mathrm{~m}$ long reduction housing 50/35 was manufactured and embedded with an additional closing gate valve, placed between the outer part of the exhaust hood and the input measuring port on the exterior of the turbine. The cylindrical carrier of the probe with a length of $4.5 \mathrm{~m}$ and a diameter of $35 \mathrm{~mm}$ was reinforced by the reduction housing which improved the precise positioning of the probe itself. The position of the probe and housing in the turbine's casing can be seen in figure 3 .

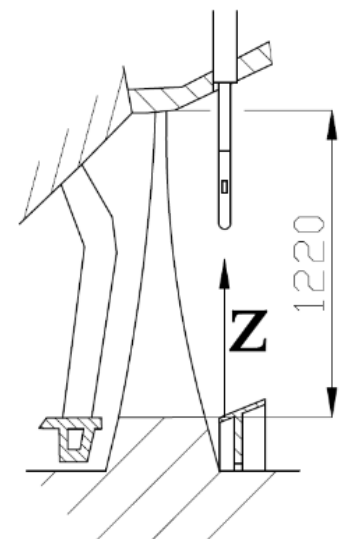

Figure 3. The probe position behind the last stage

Two different versions of the probe head of the extinction probe were used, V-1 and V-2.

The measurement began with the use of probe head $\mathrm{V}-1$. The diameter of the probe is $21 \mathrm{~mm}$ and the measurement slot is $100 \times 13 \mathrm{~mm}$, through this slot the wet steam is flowing. Perpendicular to the wet steam flow is placed a white beam of light which passes through the wet steam flow. The light is scattered on the droplets, hence the light intensity decreases (Chapter 2).

The light is drawn from an external deuteriumhalogen light source to the probe head through a fibre optics cable to the measurement slot which is restricted by the optical windows. The fibre optics was used for the incoming light signal as well as for collecting the light which passes through the measurement slot. The fibre optics is terminated by the collimators. Spectral analysis of the collected light is performed in the entire wavelength range $\lambda \sim 200 \div 1000 \mathrm{~nm}$.

In comparison with the previous data acquisition system, the light source and the spectrometer were installed on the probe carrier to avoid any error due to the movement of the fibre optics. The purging air for the optical windows and the control pipe for the probe 
opening for gaining reference signal Io is drawn in the carrier pipe.

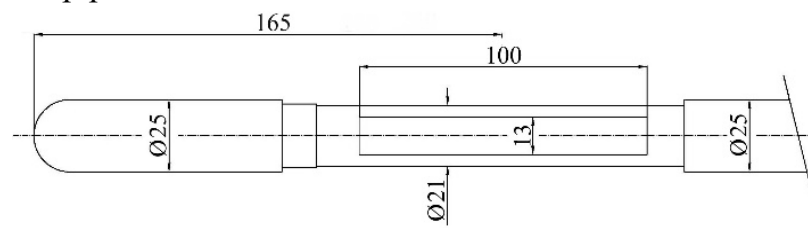

Figure 4. The main dimensions of the probe head V-1.

Due to the very high optical density of the wet steam after the last blade the measurement slot length was reduced, $\mathrm{L}=50 \mathrm{~mm}$. Probe head V-2 was use for further measurements (figure 5).

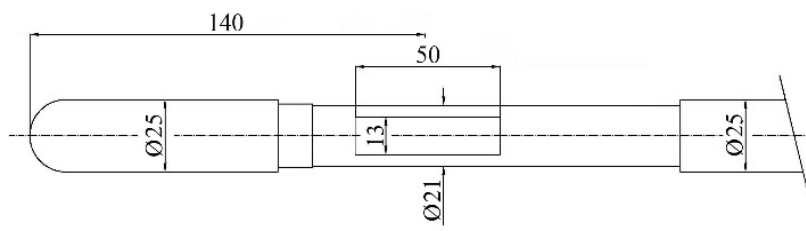

Figure 5. The main dimensions of the probe head V-2.

\subsection{Photogrammetric probe}

The measurement was carried out in a similar way to the measurement with the extinction probe [6]. The photogrammetric probe is enclosed in a stainless steel tube $50 \times 3 \mathrm{~mm}$. The head of the probe slides out of the tubing at the measurement position. This system protects the probe head during the insertion of the probe through the casing of the turbine. The camera and the objective are in the head of the probe on one side of the test section. The LED light source is fixed on the other side. The size of the test section is determined by the two ribs, as shown in figure 6 . The glass windows are purged by air. Previous experience has shown that the purging window is necessary to blow away the film of water deposited on the surface of the glass window. It is thought that the influence of the purging air curtain is negligible. When the probe is placed at the desired position in the main flow of the steam, the directions of the air and the steam flow are similar. The theoretical resolution of the probe is given by the objective lens. In this case it was cca $10 \mu \mathrm{m}$. Due to the high optical density of the wet steam flow the measurement slot was reduced from $110 \mathrm{~mm}$ to $60 \mathrm{~mm}$ in a similar way to the extinction probe.

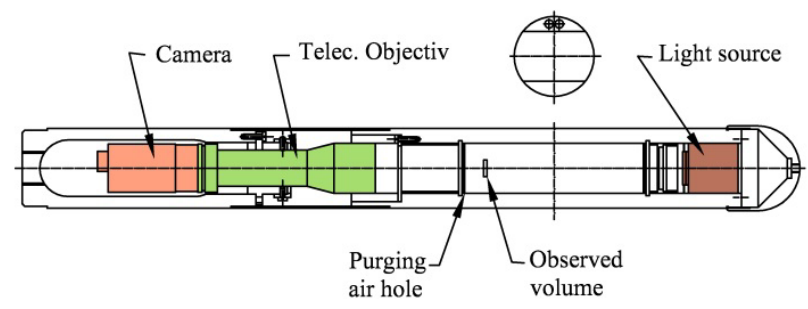

\section{Data processing}

\subsection{Steam wetness}

The size distribution functions of the droplets $\varphi(D)$ for the particular probe positions were determined by solving a system of equations (1) with the measured values of the light extinction $I / I_{o}=f(\lambda)$. The numerical solution of the equation system (determination of the function $\varphi(D)$ was done by the regularization technique RNL developed at the Department of Energy Engineering at the Faculty of Mechanical Engineering CTU in Prague [2].

From the droplets size distribution function the flowing steam wetness was determined from the amount of fine droplets.

$$
y=\frac{I}{1+I}
$$

where $I=\frac{\pi}{6} \frac{\rho_{k}}{\rho_{p}} N_{v} \int_{D_{\min }}^{D_{\max }} \varphi(D) D^{3} \mathrm{~d} D$,

$\rho_{k}$ and $\rho_{p}$ is the density of liquid and vapour respectively.

\subsection{Coarse droplets}

Unlike light scattering, the photogrammetry method requires calibration. The calibration was carried out with the standard resolution target. This target was used for testing the spatial resolution of the new data processing method. The ratio for the probe is $180 \mathrm{px} / 1 \mathrm{~mm}$.

The data processing of the required images could be manual or automatic through the use of computer vision techniques. The measurement in the turbine in ETE provided highly variable illumination conditions in the measurement slot and for most positions manual image selection was necessary.

\section{Experimental measurements}

The measurement with the extinction probe was carried out behind the last stage of the 3. LP part of the turbine $1000 \mathrm{MW}$ on the 1. block in ETE. The measurement ports are sealed by packing and closed through the use of a gate valve and it is possible to insert both probes inside the turbine when the turbine is under operation. The extinction probe required reduction housing and the photogrammetric probe can be inserted directly through the port.

The position of the symmetrically placed measurement ports is shown in figure 7 from a side view from the exhaust hood of the turbine.

Figure 6. The schema of the photogrammetric probe. 


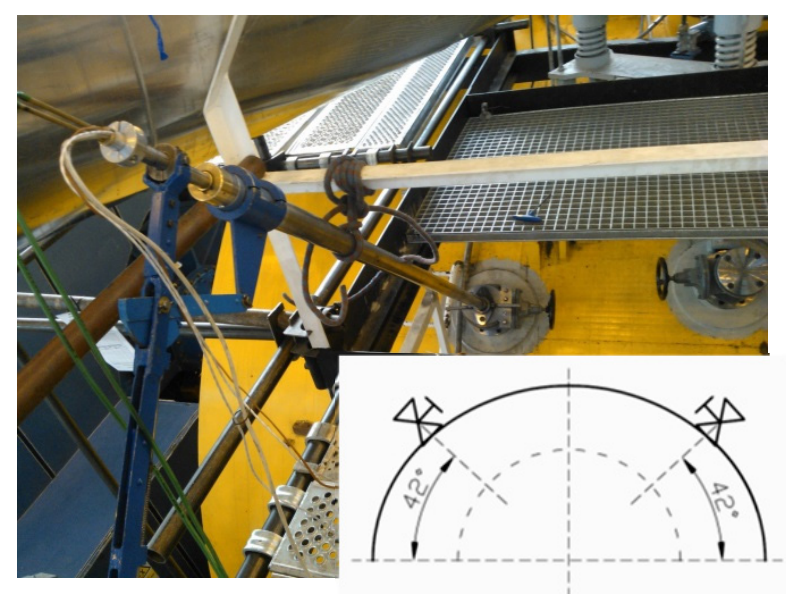

Figure 7. The photogrammetric probe inserted in to the turbine; position of the measurement ports on the left and right side.

The positioning of the probe in the radial direction can be done in several positions in order to collect the wetness distribution along the blade height.

The position of the probe's head is determined by the coordinate $\mathrm{z}$ (figure 3 ) as the position of the measurement section centre from the hub diameter of the blade.

The radial distance between the inner and outer diffusor walls is approx. $1250 \mathrm{~mm}$. Due to the radial positioning of the probe it is possible to perform a series of measurements to determine the wetness along the last blade. In this case 23 fixed radial probe positions $\mathrm{z}_{1}-\mathrm{Z}_{23}$ were chosen. In every position 10 particular measurements were done with the open and closed measurement section. The direction of the measurement slot was set according to the data about the flow field provided by DSP.

\section{Results}

The primary goal for the measurement with optical probes in the ETE was to find the wetness distribution along the last blade of the new LP part of the steam turbine with five stages. For the first time with this turbine DSP used the last blade with a length of $1220 \mathrm{~mm}$.

For the measurement of the liquid phase two optical probes were used (extinction and photogrammetric). The position of the probes is clear from figures 3 and 7 .

The presented data are only the first part of the measurement campaign. Part of the experimental research was devoted to determining the difference of the liquid phase structure along the turbine perimeter behind the last stage. The measurement with the extinction probe was performed on the left and right side of the turbine casing to find the difference. In this paper the results of the wetness distribution along the last turbine's blade from the left and right side of the turbine are presented.

The operational state of the turbine was determined by the overhaul performance $\sim 1070 \mathrm{MW}$ and the static pressure behind the last stage in the position of the measurement in the range $9.73 \div 9.98 \mathrm{kPa}$. The value of the wetness is presented in figure 8 . in the normalized form. $y=f(z)$.

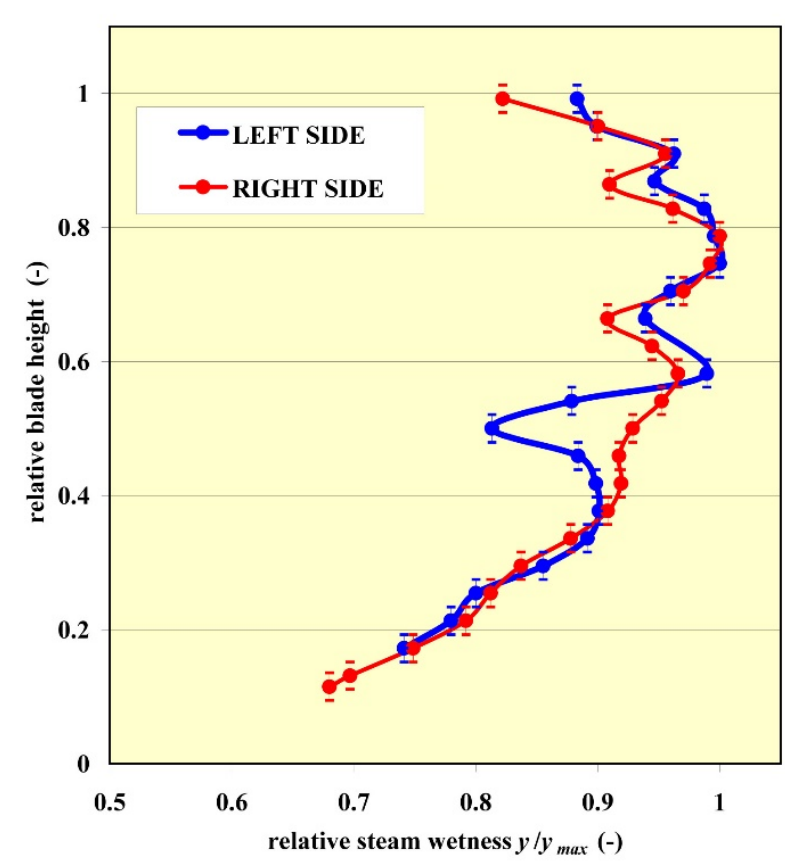

Figure 8. The wetness distribution along the last blade for the left and right side of the turbine.

The particular values of the wetness for the measurement positions are presented in figure 8 at the position of the measurement section centre. The thin line presents the size of the measurement section $(50 \mathrm{~mm})$ of the probe and borders the region of signal acquisition by the extinction probe.

The main goal for the measurement with the photogrammetric probe was to verify the ability to measure. Unless the nature of the probe is very simple the probe requires state of the art equipment. During the measurement the proper setting of the light intensity, exposure time, gain and other parameters of the camera and light source played a very important role to create an acceptable image.

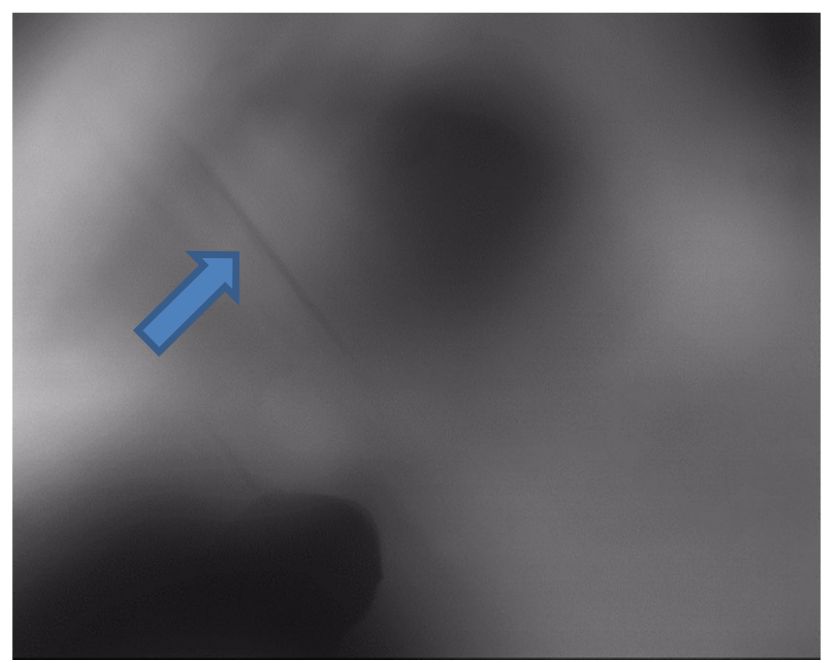

Figure 9. The path of the coarse droplet.

Figure 9 presents an image taken at the position $\mathrm{z}=1100 \mathrm{~mm}$. In the figure it is possible to see the flow 
path of the coarse droplet. The diameter of the coarse droplet is around $50 \mu \mathrm{m}$ and the velocity was determined as $300 \mathrm{~m} / \mathrm{s}$ with respect to the exposure time of $9 \mathrm{e}^{-6} \mathrm{~s}$. The flow path is very blurred in most of the captured droplets. The number of coarse droplets was not sufficient to obtain the correct statistical analysis of the size distribution function in the case of this measurement campaign. Despite this fact the results are unique and the coarse droplet in figure 9 presents the first such droplet ever captured by a camera. The results achieved with the measurement with the photogrammetric probe will be used for the further development and improvement of the probe.

\section{Conclusions}

The paper presents a brief description of the experimental research of wetness in the steam turbine $1000 \mathrm{MW}$ in the 1. block of the power station ETE.

A measurement system developed at CTU in Prague was used, which consists of extinction probes, a photogrammetric probe, auxiliary units for measurement support, and basic instruments for data acquisition and data processing. The parameters of the steam necessary for the data processing such as the admission temperature and pressure, and the emission pressure are reached through the control and measurement system ETE and from data provided by the measuring team DSP. Experimental data was processed by the numerical method RLN.

The photogrammetric probe has proven successful in the detection of coarse droplets but the quality of the captured images still needs to be enhanced.

The results are presented as an example of normalized wetness distribution along the last blade on the right and left side of the steam turbine. The measured condition was similar for both measurements.

\section{Acknowledgement}

We gratefully acknowledge the support by Grant No. 101/11/1593 of the Grant Agency of the Czech Republic and by the Grant Agency of the Czech Technical University in Prague, grant No. SGS 14/183.

The authors gratefully acknowledge the support of all colleagues from DSP and the ČEZ company, who helped in the completion of this project.

We gratefully acknowledge the technical and measurement assistance of our colleague Petr Stř́žz.

\section{References}

1. Bohren, C.F., Huffman, D.R.: Absorption and Scattering of Light by Small Particles. John Wiley \& Sons, Inc., USA, 1998

2. Kolovratník, M.: Extinkční sondy pro měření v parních turbínách. Habilitační práce, Praha, 2004

3. M. Kolovratník, O. Bartoš, , Proc. Int. Conf. Experimental Fluid Mechanics, 358-361, (2013)
4. X. Cai,L. Wang, Y. Pan, X. Ouyan, J. Shen, J. Thermal Science. 10: 123-126, (2001)

5. O. Bartoš, X. Cai, M. Kolovratník, The Cambridge Baumann Centenary Conference on Wet Steam Flows (Cripps Court Conference Centre, Magdalene College, Cambridge, UK; 10-11 September 2012)

6. O. Bartoš, X. Cai, M. Kolovratník, Proc. Int. Conf. Experimental Fluid Mechanics, 77-81, (2013) 